\title{
Profile: Vadu Health and Demographic Surveillance System Pune, India
}

\section{Rutuja Patil ${ }^{1,2}$, Sudipto Roy ${ }^{1,2}$, Vijendra Ingole ${ }^{1,4}$, Tathagata Bhattacharjee ${ }^{1,3}$, Bharat Chaudhary $^{1}$, Pallavi Lele ${ }^{1,3}$, Siddhivinayak Hirve ${ }^{1}$, Sanjay Juvekar ${ }^{1,3}$, on behalf of Vadu HDSS team ${ }^{1}$}

\footnotetext{
${ }^{1}$ KEM Hospital Research Centre Pune (KEMHRC), Vadu Rural Health Program, India

${ }^{2}$ Usher Institute, College of Medicine and Veterinary Medicine, University of Edinburgh, Edinburgh UK

${ }^{3}$ INDEPTH Network, Accra, Ghana

${ }^{4}$ ISGlobal, Barcelona, Spain
}

T adu Health and Demographic Surveillance System (VaduHDSS), a surveillance system initiated in 2002, is run by Vadu Rural Health Program of the KEMHRC Pune. Every six month, the Vadu HDSS collects data on pregnancies, births, marriages, migrations, deaths and assesses causes of deaths using verbal autopsies in a population of 160000 individuals residing in about 48000 households in 22 villages. By virtue of its longitudinal data generation practices the VaduHDSS facilitates national and globally relevant health research to generate evidence for informed health policy decisions.

Availability of reliable empirical health and demographic data are crucial to understand the burden and trends of health conditions/diseases and plan health interventions. Typically, such data are obtained from sample populations, which is then used to calculate estimates for the larger community with the help of statistical analyses and modeling techniques. Though these methods are robust and can result in fairly accurate estimates, these are heavily dependent on sampling techniques and sample characteristics and can have significant errors in estimates. One method to improve this is to establish a health and demographic surveillance system (HDSS). An HDSS involves an ongoing, long-term monitoring of vital events, demographic characteristics and health status of a geographically defined population. The complete population within an HDSS is under surveillance and thus relevant data are available for all its individuals. An HDSS enables us to monitor trends in diseases and conditions and track mortality rates and help to fill gaps in health-related data. Additionally, it provides a platform to conduct health research studies.

Here we present the profile of an HDSS in a rural part of Pune district, India, set up by KEM Hospital Research Centre Pune. We describe the surveillance system and report some key findings from it, including the advantages of a HDSS.

\section{WHY WAS THE VADUHDSS SET UP?}

KEM Hospital (KEMH), a 106-year-old multi-specialty, 550 bedded, tertiary care hospital in Pune city [1], started providing primary health care to rural communities in and around Vadu village in the early 
part of the decade of 1970 as the area lacked adequate health care facilities. It started a secondary level health facility with support from public health systems by establishing a 30-bedded hospital named Shirdi Sai Baba Rural Hospital in 1987. In 1988, KEMH added a community-based outreach program [2], termed as Vadu Rural Health Program (VRHP), catering to the primary health care needs of the surrounding rural population simultaneously. To enhance the quality of health care, KEM Hospital Research Centre (KEMHRC), a sister concern of KEMH which focuses on research, started conducting health research in VRHP area in 1983 [3]. With an increasing realization of the importance of social determinants of health, there was a felt-need to better understand the complex interaction between socio-demographic characteristics and health at the individual and population level. With this in view, the Vadu Health and Demographic Surveillance System (VaduHDSS) was initiated in a geographically contiguous population of 50000 individuals covering 22 villages in 2002, with seed grant from the Gates Institute for Population and Reproductive Health, Johns Hopkins University Bloomberg School of Public Health. The overarching objectives of VaduHDSS are:

1) To continuously monitor the demographic dynamics in a rural population in terms of births, deaths, cause of death (COD) and migration

2) To facilitate clinical, epidemiological, socio-behavioural and intervention health research

3) To establish a platform for evaluation of public health interventions

4) To generate evidence for informed health policy decisions

The HDSS facilitates national and globally relevant health research in line with its mission to "Provide evidence-based, sustainable and rational health care solutions for the rural population using globally relevant community-based ethical research".

\section{WHAT DOES IT COVER NOW?}

Vadu HDSS currently includes 160000 individuals residing in 22 villages of Shirur and Haveli Block of Pune district in Maharashtra, India. Vadu HDSS has experienced a rise in the population from an initial 50000 in 2002 to 160000 in 2018. While VaduHDSS area was primarily an agrarian community in 2002, today a significant proportion of population is employed in industries. Rapid growth of industries has resulted in newer occupational opportunities $[4,5]$ leading to in-migration of younger generation from all over the country, which is indicated by the bulging mid-section of the population pyramid (Figure 1 ). The following conceptual framework (Figure 2) describes how VaduHDSS is inclusive in its approach and how the population is central to its activities.

VaduHDSS (latitude $18^{\circ} 30$ to $18^{\circ} 47 \mathrm{~N} \&$ longitude $73^{\circ} 58$ to $74^{\circ} 12 \mathrm{E}$ ) covers a geographical area of $232 \mathrm{~km}^{2}$ with an average altitude of $560 \mathrm{~m}$ (Figure 3). There are three seasons: Monsoons June-October with mean

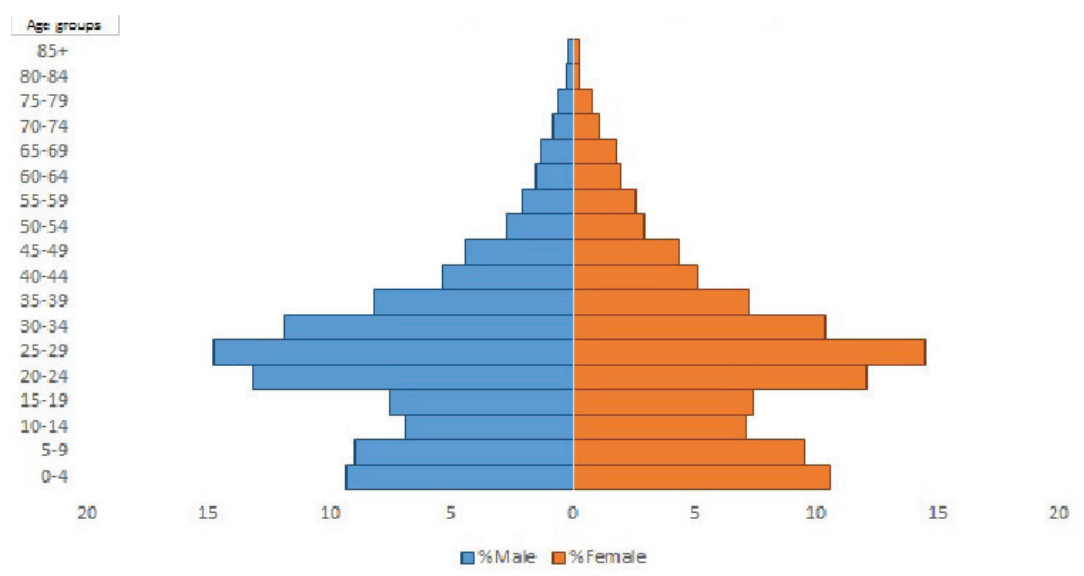

Figure 1. Population pyramid for Vadu Health and Demographic Surveillance System (VaduHDSS) area. 


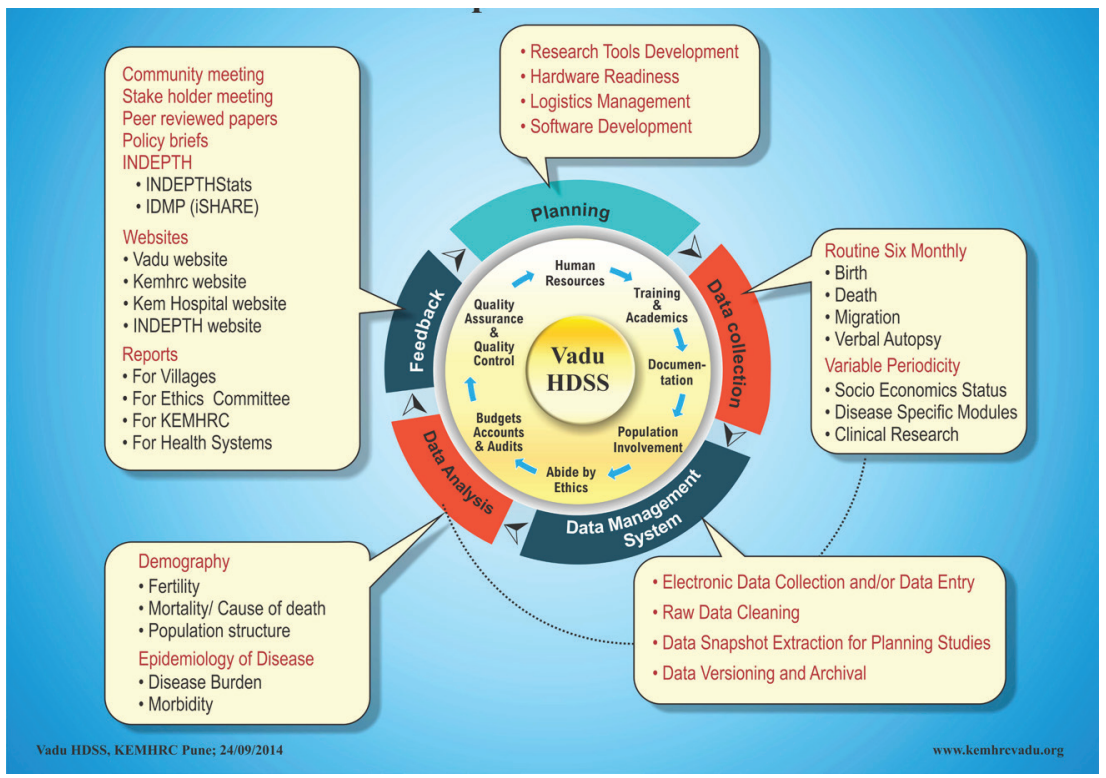

Figure 2. Vadu Health and Demographic Surveillance System (VaduHDSS) conceptual framework.

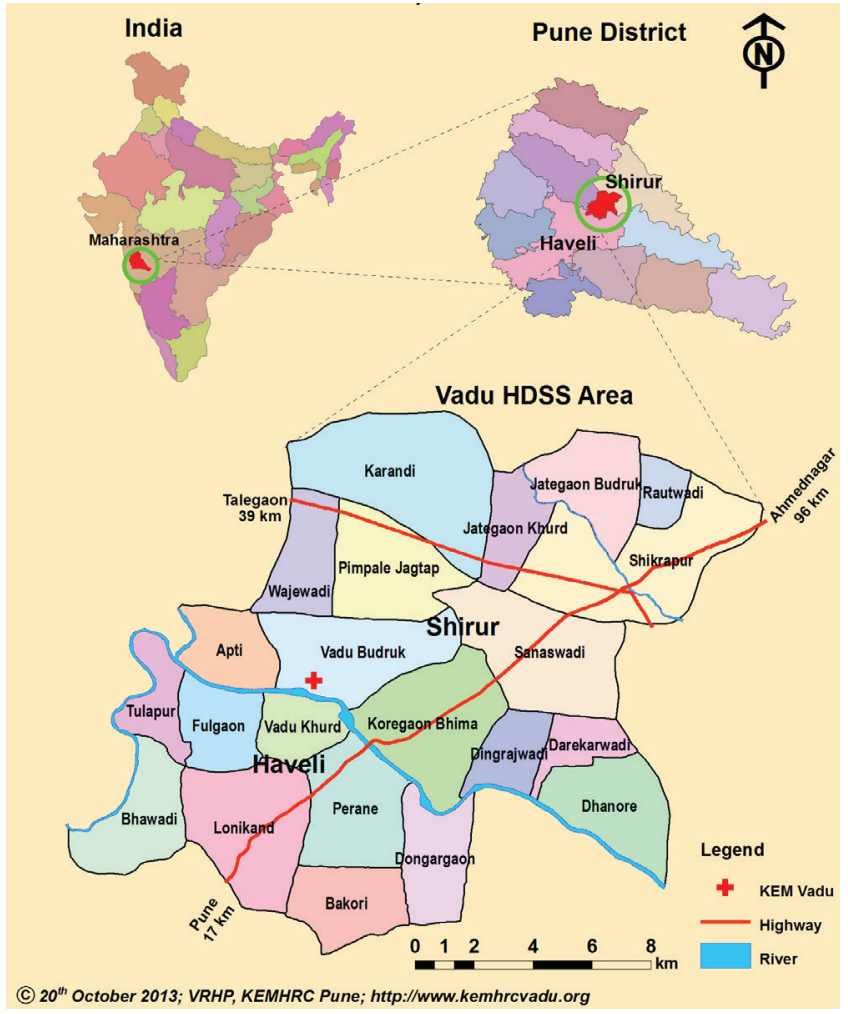

Figure 3. Vadu Health and Demographic Surveillance System (VaduHDSS) area map. annual rainfall of $720 \mathrm{~mm}$, Winter October-February with minimum temperatures between $7-9^{\circ} \mathrm{C}$ and Summer February-May with maximum temperatures of $40-42^{\circ} \mathrm{C}$.

We collect data from local residents who are either native or those who migrate to this area with an intention to stay for more than three months. All households in VaduHDSS area are visited once every six months during which data are collected on births, deaths, marriage, migrations, pregnancy status and outcomes of every woman in reproductive age group and self-reported common illnesses. Verbal Autopsy (VA) is conducted for every death.

We have established some sub-cohorts within VaduHDSS to look at specific health conditions. A cohort of 15000 children aged $<5$ years to assess nutritional status using anthropometry was established in 2017. We plan to follow each child till the individual reaches 12 years. A NonCommunicable Diseases Risk Factor surveillance (NCDRF cohort of 2400 individuals) was conducted in 2004 with support from WHO-NCD division and the same cohort was followed up, with institutional support, in 2017 to determine changes in NCD-RF [6,7]. Under the study of Global Ageing (WHO-SAGE) a cohort of 440 elderly individuals of 55 years and older was established to know cognitive elderly functioning and health status assessment

$[8,9]$. Another cohort to understand Burden of Obstructive Lung Disease (BOLD) was established in 2007 to estimate COPD burden/ its phenotypes using spirometry \& clinical assessment. This cohort of 3400 adults over 25 years of age, was established in collaboration with Imperial College London [10,11]. This cohort is now being followed up to determine the progress of COPD disease in these individuals. A cohort of 6000 children under 15 years of age is currently being followed up to estimate the burden of enteric fever [12]. Timelines describing cohorts developed are described in the Gantt chart (Figure 4). 
* Vital indicators include births; deaths with VA; marital status; in and out migration; reproductive history of married women

Figure 4. Timelines describing cohorts development at Vadu Health and Demographic Surveillance System (VaduHDSS).

\section{WHAT HAS BEEN MEASURED AND HOW HAVE HDSS DATABASES BEEN CONSTRUCTED?}

VaduHDSS is a member of International Network for the Demographic Evaluation of Populations and Their Health (INDEPTH) that conducts longitudinal surveillance for monitoring and evaluation of population health in low and middle-income countries. The routine surveillance round collects demographic information as per Table 1. Additionally, all deaths within HDSS area are recorded and subjected to VA using an adapted version of WHO VA tools followed by physician assigned COD using ICD10 classification (International Classification of Diseases-Version10). We are now migrating to electronic assessment of COD. Changes such as new location and household change are registered and updated in the database.

Table 1. Demographic information collected during HDSS round

\begin{tabular}{|c|c|}
\hline DATA FORMS & INFORMATION COLIEGTED \\
\hline Individuals & Name, Individual ID, occupation, education, age, marital status, relationship with household head, date of birth \\
\hline Births & Name, ID, sex of child, date of birth, mother's and father's ID, place of birth, birth weight \\
\hline Deaths & Causes of deaths, date of deaths, place of deaths, VA \\
\hline Immigration & Date of in-migration, reason for migration \\
\hline Outmigration & Date of out-migration, reason for migration, destination of migration \\
\hline Pregnancy & Outcome of pregnancy, date of last cycle \\
\hline
\end{tabular}

ID - identification, VA - verbal autopsy

Data collection at VaduHDSS is done by its Field Research Assistants (FRA) who are local residents of the VaduHDSS area. The FRAs are trained to collect research data from the community, using ethical practices. This training has in turn enhanced the capacities of community in using technology and understanding health. This data are further checked for quality on field by the field research supervisors and later by the data managers once the data are uploaded on the servers on a weekly basis.

The first round of VaduHDSS data collection was in 2002. Initial rounds of HDSS data collection were paper-based followed by data entry using a FoxPro based software. With increasing availability of technology, we started electronic data capture using laptops in 2007. This was done using an application developed using PHP My Admin software for front-end application and MySQL database. Shifting from paper based to electronic data capture helped up to reduce data-entry errors and other errors due to built-in quality checks. Moreover, it has substantially reduced time and cost of data collection. In 2013, we started data collection on electronic tablet using an android application based on SQLite software, developed in house. Current data flow is described in Figure 5. From July 2019 we plan to move to more opensource platform "Survey solutions" for long term sustainability. Since 2009 we have initiated an open data access policy. Our data are available in public domain on the INDEPTH-iShare website along with the metadata, thus providing anonymized longitudinal microdata to researchers across the globe. 


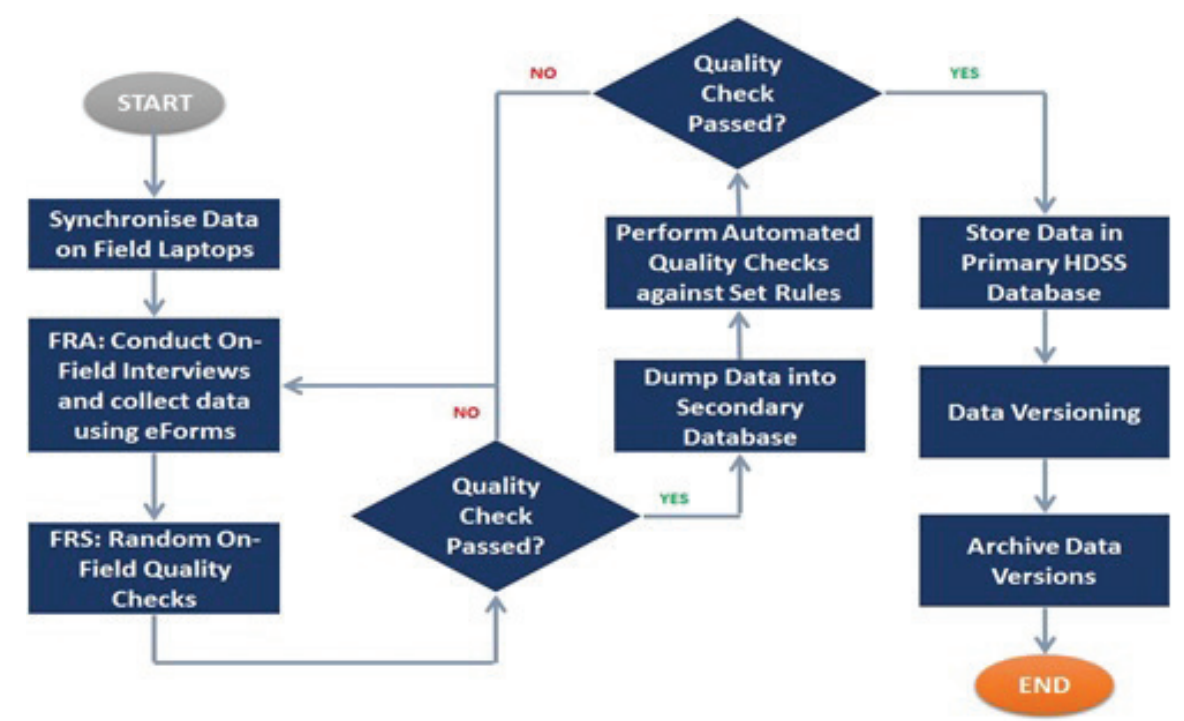

Figure 5. Vadu Health and Demographic Surveillance System (VaduHDSS) data flow.

\section{HOW HAS VADUHDSS DATA BEEN USED}

VaduHDSS has contributed to national programs on immunization, tubectomy, vasectomy, tuberculosis control, childhood disability identification program and development of community health volunteer schemes. Examples of some study findings which have made their way to implementation by the public health system include Sprinkles micronutrient powder [13,14] and iron fortified wheat flour [15] as well as vaccine studies on Rota virus vaccine [16-21]. Studies conducted in VaduHDSS, in addition to providing evidence to government, have created significant scientific literature as outcome of its studies [22]. A list of publications is available on www.kemhrcvadu.org/index.php/academics/publications.

\section{KEY FINDINGS FROM VADUHDSS}

VaduHDSS has experienced a steep rise in the population since 2002 leading to a current population density of 636 people per square km. Other demographic characters for the years 2009, 2013 and 2017 along with the comparative information available for contemporary time period from the Indian government records (NITI Aayog) are described in details in Table 2.

Table 2. Demographic characteristics of VaduHDSS in 2009, 2013 and 2017 compared to the government figures for state

\begin{tabular}{|c|c|c|c|c|c|c|c|}
\hline & & \multicolumn{2}{|r|}{2009} & \multicolumn{2}{|r|}{2013} & \multicolumn{2}{|r|}{2017} \\
\hline & & $\begin{array}{l}\text { Vadu } \\
\text { HDSS }\end{array}$ & $\begin{array}{l}\text { NITI Aayog } \\
\text { (Maharashtra) }\end{array}$ & $\begin{array}{l}\text { Vadu } \\
\text { HDSS }\end{array}$ & $\begin{array}{l}\text { NITI Aayog } \\
\text { (Maharashtra) }\end{array}$ & $\begin{array}{l}\text { Vadu } \\
\text { HDSS }\end{array}$ & $\begin{array}{c}\text { NITI Aayog } \\
\text { (Maharashtra) }\end{array}$ \\
\hline 2 & Mid year population & 97996 & NA & 131105 & NA & 148256 & NA \\
\hline 4 & Households - mid year count & 30293 & NA & 46594 & NA & 48347 & NA \\
\hline 5 & Sex ratio at birth - per 1000 & 812 & $893(2009-11)$ & 910 & $902(2011-13)$ & 884 & $878(2013-15)$ \\
\hline 7 & Population density per sq km & 422 & NA & 565 & NA & 636 & NA \\
\hline 8 & Crude birth rate & 17.66 & $17.66(2016)$ & 17.6 & $16.5(2013)$ & 20 & $15.9(2016)$ \\
\hline 9 & Crude death rate & 4 & $6.7(2009)$ & 4 & $6.2(2013)$ & 3 & $5.9(2016)$ \\
\hline 10 & Total fertility rate & 1.5 & $1.9(2009)$ & 1.6 & $1.8(2013)$ & 1.6 & $1.8(2016)$ \\
\hline 11 & Neonatal mortality rate per thousand live births & 11.62 & $18(2011)$ & 3.47 & $17(2013)$ & 3.03 & NA \\
\hline 12 & Infant mortality rate & 12 & $31(2009)$ & 6 & $24(2013)$ & 6 & $19(2016)$ \\
\hline 13 & Under five mortality rate & 18 & $28(2011)$ & 10 & $26(2013)$ & 8 & $18(2015)$ \\
\hline 14 & Life expectancy at birth (male) & 77 & $67.9(2006-10)$ & 72 & $69.4(2009-13)$ & 77 & $69.9(2010-14)$ \\
\hline 15 & Life expectancy at birth (female) & 76 & $71.9(2006-10)$ & 77 & $73.4(2009-13)$ & 79 & $73.6(2010-14)$ \\
\hline
\end{tabular}

NA - not available 
In 2017, about 56\% individuals were males which has been about the same since 2009. Around 26\% of the total population had completed primary school. Children aged $<15$ years constituted $25 \%$ and those $<5$ years constituted $10 \%$ of the population while only $4 \%$ of the population was $>65$ years. Other background characteristics for three time points, ie, 2009, 13 and 17 are given in Table 3.

Morbidity surveys indicated that $1.7 \%$ of total population reported fever in past two weeks, while $1 \%$ reported fever with cough. Of the population, $0.6 \%$ had diarrhea in previous two weeks. Hypertension, diabetes and asthma were significantly higher in individuals aged $>50$ years with proportions of $5.55 \%$, $5.14 \%$ and $1.86 \%$ respectively. These are reported to be significantly highest in farmers, while fever was reported to be highest in individuals working in manufacturing/service industry.

Table 3. Background characteristics in years 2009, 2013 and 2017

\begin{tabular}{|c|c|c|c|c|c|c|c|}
\hline \multirow[t]{2}{*}{ Variabie } & \multirow[t]{2}{*}{ Catienorites } & \multicolumn{2}{|c|}{2009} & \multicolumn{2}{|c|}{2013} & \multicolumn{2}{|c|}{2017} \\
\hline & & Frequency & Percent & Frequency & Percent & Frequency & Percent \\
\hline \multirow[t]{3}{*}{ Sex } & Female & 44572 & 43.41 & 55839 & 41.46 & 65679 & 43.72 \\
\hline & Male & 58098 & 56.59 & 78854 & 58.54 & 84558 & 56.28 \\
\hline & Total & 102670 & 100.00 & 134693 & 100.00 & 150237 & 100.00 \\
\hline \multirow[t]{9}{*}{ Education completed } & $<$ Primary school & & & 29364 & 13.09 & 45008 & 12.84 \\
\hline & Primary school & & & 59369 & 26.47 & 90256 & 25.74 \\
\hline & Secondary school & & & 43613 & 19.44 & 63809 & 18.2 \\
\hline & High school & & & 33804 & 15.07 & 60290 & 17.2 \\
\hline & Graduation & & & 12918 & 5.76 & 28497 & 8.13 \\
\hline & Post-graduation & & & 3197 & 1.43 & 6326 & 1.80 \\
\hline & No schooling & & & 41850 & 18.66 & 56297 & 16.06 \\
\hline & Others & & & 197 & 0.09 & 140 & 0.04 \\
\hline & Total & & & 224312 & 100.00 & 350623 & 100.00 \\
\hline \multirow[t]{8}{*}{ Marital status } & Currently married & & & 111087 & 49.52 & 174256 & 50.45 \\
\hline & Currently re-married & & & 187 & 0.08 & 532 & 0.15 \\
\hline & Separated & & & 525 & 0.23 & 900 & 0.26 \\
\hline & Divorced & & & 91 & 0.04 & 158 & 0.05 \\
\hline & Widowed & & & 7470 & 3.33 & 9727 & 2.82 \\
\hline & Never married & & & 104535 & 46.6 & 158089 & 45.77 \\
\hline & Others & & & 417 & 0.18 & 1745 & 0.51 \\
\hline & Total & & & 224312 & 100.00 & 345407 & 100.00 \\
\hline \multirow[t]{7}{*}{ Age categories female } & Less than $1 \mathrm{y}$ & 1008 & 2.26 & 1416 & 2.54 & 1449 & 2.21 \\
\hline & $1-4.99 \mathrm{y}$ & 3634 & 8.15 & 4797 & 8.59 & 5711 & 8.70 \\
\hline & $5-14.99 y$ & 7752 & 17.39 & 9215 & 16.50 & 10342 & 15.75 \\
\hline & $15-28.99 \mathrm{y}$ & 14711 & 33.01 & 18130 & 32.47 & 20460 & 31.15 \\
\hline & $29-64.99$ y & 15546 & 34.88 & 19982 & 35.79 & 24728 & 37.65 \\
\hline & More than $65 \mathrm{y}$ & 1921 & 4.31 & 2299 & 4.12 & 2989 & 4.55 \\
\hline & Total & 44572 & 100 & 55839 & 100.00 & 65679 & 100.00 \\
\hline \multirow[t]{7}{*}{ Age categories male } & Less than $1 \mathrm{y}$ & 1243 & 2.14 & 1518 & 1.93 & 1618 & 1.91 \\
\hline & $1-4.99 \mathrm{y}$ & 4336 & 7.46 & 5641 & 7.15 & 6426 & 7.60 \\
\hline & $5-14.99 y$ & 9390 & 16.16 & 11413 & 14.47 & 12693 & 15.01 \\
\hline & $15-28.99 \mathrm{y}$ & 21877 & 37.66 & 31553 & 40.01 & 28740 & 33.99 \\
\hline & $29-64.99$ y & 19226 & 33.09 & 26410 & 33.49 & 32215 & 38.10 \\
\hline & More than $65 \mathrm{y}$ & 2026 & 3.49 & 2319 & 2.94 & 2866 & 3.39 \\
\hline & Total & 58098 & 100.00 & 78854 & 100.00 & 84558 & 100.00 \\
\hline \multirow[t]{7}{*}{ Age categories both sexes } & Less than $1 \mathrm{y}$ & 2251 & 2.19 & 2934 & 2.18 & 3067 & 2.04 \\
\hline & $1-4.99 \mathrm{y}$ & 7970 & 7.76 & 10438 & 7.75 & 12137 & 8.08 \\
\hline & $5-14.99 y$ & 17142 & 16.70 & 20628 & 15.31 & 23035 & 15.33 \\
\hline & $15-28.99 \mathrm{y}$ & 36588 & 35.64 & 49683 & 36.89 & 49200 & 32.75 \\
\hline & $29-64.99 y$ & 34772 & 33.87 & 46392 & 34.44 & 56943 & 37.90 \\
\hline & More than $65 \mathrm{y}$ & 3947 & 3.84 & 4618 & 3.43 & 5855 & 3.90 \\
\hline & Total & 102670 & 100.00 & 134693 & 100.00 & 150237 & 100.00 \\
\hline
\end{tabular}


In addition to this, in a nutritional survey in under-five children, mid-upper arm circumference measurements indicated that $16 \%$ of children were mildly undernourished, $5 \%$ were moderately undernourished and 1.2\% were severely undernourished. Analysis of data collected from NCD and SAGE cohorts in $2005-$ 06 almost two-thirds of men and half of women in VaduHDSS chewed tobacco daily [23]. Considerable proportion of the survey sample in VaduHDSS area has high blood pressure both in men (25.5\%) and women (21.6\%) [24]. Reported prevalence of physical inactivity was higher (58\%) [25] and prevalence of chronic conditions was also found to be high in both men (28.6\%) and women (35.8\%) [6]. Prevalence of self-reported chronic condition in adults over 50 years of age in 2005-06 was 28.6 in men and 35.8 in women $[15,16]$.

Non-communicable diseases are the most common causes of death in VaduHDSS population. This is reflective of the changing epidemiology of common diseases in India, even in rural areas. The second highest COD is accidental deaths owing to increasing availability and use of vehicles in the newly industrialized area and changing socio-economic status. Moreover, mortality is associated with ambient temperature in VaduHDSS and has been analyzed in context of various confounding factors $[26,27]$.

VaduHDSS data indicates that between 2004 and 2016 proportion of agricultural cultivators reduced from $22.58 \%$ to $13.69 \%$ while agricultural landowners decreased from $61 \%$ to $25 \%$ indicating reduction in people's dependency on agriculture and increased inclination towards industrial jobs as indicated by the increased proportion of individuals working in small and medium scale industries from 36\% in 2004 to $44 \%$ in 2015 .

The socio-economic development of this area is reflected in increase in use of flushed toilet facilities by $7 \%$ and increase in use of electricity by $11 \%$ between 2004-05 and 2014-15. Additionally, proportion of households using Liquefied Petroleum Gas for cooking increased from 55\% to $77.45 \%$ in ten years. One important change that this area has seen since 2002 is the growth of mixed health care delivery sector, with both private and government health facilities providing health services.

Since 2002 nearly 68 research studies have been conducted based on the VaduHDSS. VaduHDSS has a strong interest in health of women and children. A study conducted in 2012 on marriage preparedness among adolescent girls reported that almost 90\% of women marry between the ages of 18 and 21 years. The most common factors associated with early marriage were poor economic conditions, societal pressure and concern about the security of girls due to perceived unsafe environment. The studies at VaduHDSS on water, sanitation and hygiene (WASH) infrastructure and practices in women conducted in 2016 reported that prevalence of open defecation in HDSS area is low and most people have access to WASH installations in or close to their living quarters.

VaduHDSS participation in conducting large community-based trials for meningitis, measles, typhoid, rotavirus and pneumococcal vaccines is one important contribution towards the development of safe, efficacious and affordable vaccines global use [15-20,22-25,28-30]. VaduHDSS has always led the technology portfolio within INDEPTH network and was instrumental in the development of online data repository iSHARE (www.INDEPTH-iSHARE.org). VaduHDSS utilizes technology for providing health services to rural population at remote station through its micro-health centre (MHC). MHC is a ready-to-use integrated health system for delivery of community-based primary health care. MHC generates medical data for a national database using cloud-enabled health care database management system [31].

\section{IMPORTANT COLLABORATIONS}

VaduHDSS, since inception, being part of INDEPTH Network has mutually supported its activities. Other than the regular HDSS VaduHDSS has lead nearly ten working groups including the Non-communicable diseases, communication and policy, indoor air pollution, and data sharing groups. VaduHDSS has leveraged INDEPTH partnership for developing and strengthening abilities to develop and work on multicentric research projects projects. 
VaduHDSS has developed a portfolio on research in respiratory health over the past decade and is currently a part of RESPIRE a global health research unit focusing on respiratory health [32,33], that aims to conduct research to reduce mortality and morbidity due to respiratory conditions. In past, estimating the disease burden of influenza [28,29,34] and determining the incidence of acute respiratory infections [35] were the aims of two studies in the acute respiratory illness domain. Regarding chronic respiratory conditions, VaduHDSS has conducted a study to estimate the prevalence of obstructive lung diseases $[10,11,36]$ in the area under the BOLD collaboration. VaduHDSS has also conducted research into the health effects of indoor air pollution (IAP), including estimating the prevalence of biomass fuel use and an intervention study using improved cook-stoves to reduce IAP [37-41]. VaduHDSS experience in respiratory health research and a well-established research infrastructure offers a conducive environment to conduct research within RESPIRE. Additionally, the ability of HDSS to support respiratory health research has been observed in the successful conduct of the ANISA study in Bangladesh [42].

\section{STRENGTHS AND CHALLENGES}

VaduHDSS has its strength embedded in its field staff who are local villagers, This, in other words mean that at times, the field staff are members of participating households. The Field staff in VaduHDSS are known as the Field Research Assistants (FRA) who themselves are trained to conduct few aspects of community based research. They are trained with good clinical practices techniques so as to ensure ethical conduct during data collection [22]. The second strength is its data management team that is capable of generating quality data collection tools, timely cleaning and provision of data for researchers to use and timely data sharing in public domain $[43,44]$.

The analysis and use of the voluminous amounts of data generated in the HDSS can be challenging. This is one reason VaduHDSS encourages open data sharing, described in the next section and collaborations throughout the world to use the data.

\section{DATA SHARING AND COLLABORATION}

The data are shared within institution and with outsiders. Within institution, the data are shared for data analysis, publication, as sampling frame for newer studies and for planning studies. The data for outsiders are shared directly in public domain using INDEPTH Data Repository through iSHARE along with the metadata following the Data Documentation Initiative (DDI3) standards (www.INDEPTH-iSHARE.org).

Acknowledgements: We thank all residents of VaduHDSS who have contributed with their household's demographic information to this HDSS data and continue to provide us with their information selflessly. We appreciate all our Field Research Staffs for their patience in repeatedly getting trained and going to same households again $\&$ again for years together for data collection. Thank to clinicians helping in assigning COD to VAs, our IT team for responsible data management and KEM leadership (Dr Laila Garda and Dr VS Padbidri the present \& ex directors respectively). Mrs Rajlaxmi Rangan, Finance Manager for innovative mechanisms in finance management conducive for HDSS. Support from all administrative staffs since inception of VaduHDSS is much appreciated.

Funding: KEMHRC Pune provide core funding for running HDSS and related activities. The authors declare no conflict of interest.

Authorship contributions: RP, SR and VI wrote the first draft of this manuscript. SJ conceptualized the paper and supported the authors in drafting the text. TB contributed to specific relevant sections. TB, BC, PL and SJ contributed to the functioning of the activity described. SH gave critical comments to the draft manuscript. All authors checked the paper for the important intellectual content.

Competing interests: The authors completed the Unified Competing Interest form at www.icmje.org/coi_disclosure.pdf (available upon request from the corresponding author), and declare no conflicts of interest. 
1 KEM Hospital Pune. 2018. Available: http://kemhospitalpune.org/. Accessed: 5 May 2019.

2 Patil R, Roy S, Juvekar S. Public - Private Partnership for providing quality health-care services in India - Vadu Rural Health Program Experience. The Asian Man. 2016;10:216-21. doi:10.5958/0975-6884.2016.00032.3

3 Vadu Rural Health Program. 2014. Available: www.kemhrcvadu.org, Accessed: 6 May 2019.

4 Office of the Registrar General \& Census Commissioner India . Census of India. 2001.

5 Directorate of Economics and Statistics Maharashtra. Socio-Economic Review and District Statistical Abstract of Pune District. 2004.

6 Van Minh H, Ng N, Juvekar S, Razzaque A, Ashraf A, Hadi A, et al. Self-reported prevalence of chronic diseases and their relation to selected sociodemographic variables: a study in INDEPTH Asian sites, 2005. Prev Chronic Dis. 2008;5:A86. Medline: 18558036

7 Hall MAK, Stephenson RB, Juvekar S. Social and logistical barriers to the use of reversible contraception among women in a rural Indian Village. J Health Popul Nutr. 2008;26:241-50. Medline:18686557

8 Kowal P, Kahn K, Ng N, Naidoo N, Abdullah S, Bawah A, et al. Ageing and adult health status in eight lower-income countries: the INDEPTH WHO-SAGE collaboration. Glob Health Action. 2010;3 SUPPL. 2:11-22. Medline:20959878 doi:10.3402/gha.v3i0.5302

9 Hirve S, Juvekar S, Lele P, Agarwal D. Social gradients in self-reported health and well-being among adults aged 50 years and over in Pune District, India. GHA. 2010;3:2128. doi:10.3402/gha.v3i0.2128

10 André FS. Amaral, Jaymini Patel, Bernet S. Kato, Daniel O. Obaseki, Hervé Lawin, Wan C. Tan, Sanjay K. Juvekar, Imed Harrabi, Michael Studnicka, Emiel F. M. Wouters, Li-Cher Loh, Eric D. Bateman, Kevin Mortimer, A. Sonia Buist, Peter G. J. Burney for the BCRG. Airflow obstruction and use of solid fuels for cooking or heating: BOLD results. AJRCCM. 2017;1-43.

11 Grønseth R, Erdal M, Tan WC, Obaseki DO, Amaral AFS, Gislason T, et al. Unemployment in chronic airflow obstruction around the world: Results from the BOLD study. Eur Respir J. 2017;50:1700499. Medline:28931661 doi: 10.1183/13993003.00499-2017

12 John J, Bavdekar A, Rongsen-Chandola T, Dutta S, Kang G. Estimating the incidence of enteric fever in children in India: A multi-site, active fever surveillance of pediatric cohorts. BMC Public Health. 2018;18:594-6. Medline:29724223 doi:10.1186/s12889-018-5498-2

13 Hirve S, Bhave S, Bavdekar A, Naik S, Pandit A, Schauer C, et al. Low dose 'Sprinkles'-an innovative approach to treat iron deficiency anemia in infants and young children. Indian Pediatr. 2007;44:91-100. Medline:17351300

14 Hirve S, Martini E, Juvekar SK, Agarwal D, Bavdekar A, Sari M, et al. Delivering sprinkles plus through the integrated child development services (ICDS) to reduce anemia in pre-school children in India. Indian J Pediatr. 2013;80:990-5. Medline:23723079 doi:10.1007/s12098-013-1063-2

15 Muthayya S, Thankachan P, Hirve S, Amalrajan V, Thomas T, Lubree H, et al. Iron fortification of whole wheat flour reduces iron deficiency and iron deficiency anemia and increases body iron stores in Indian school-aged children. J Nutr. 2012;142:1997-2003. Medline:23014487 doi:10.3945/jn.111.155135

16 Kulkarni PS, Desai S, Tewari T, Kawade A, Goyal N, Garg BS, et al. A randomized Phase III clinical trial to assess the efficacy of a bovine-human reassortant pentavalent rotavirus vaccine in Indian infants. Vaccine. 2017;35:6228-37. Medline:28967523 doi:10.1016/j.vaccine.2017.09.014

17 Kawade A, Babji S, Kamath V, Raut A, Kumar CM, Kundu R, et al. Immunogenicity and lot-to-lot consistency of a ready to use liquid bovine-human reassortant pentavalent rotavirus vaccine (ROTASIIL - Liquid) in Indian infants. Vaccine. 2019;37:2554-60. Medline:30955982 doi:10.1016/j.vaccine.2019.03.067

18 Bhandari N, Rongsen-Chandola T, Bavdekar A, John J, Antony K, Taneja S, et al. Efficacy of a monovalent human-bovine (116E) rotavirus vaccine in Indian children in the second year of life. Vaccine. 2014;32:A110-6. Medline:25091663 doi:10.1016/j.vaccine.2014.04.079

19 Bhandari N, Rongsen-Chandola T, Bavdekar A, John J, Antony K, Taneja S, et al. Efficacy of a monovalent human-bovine (116E) rotavirus vaccine in Indian infants: a randomised, double-blind, placebo-controlled trial. Lancet. 2014;383:213643. Medline:24629994 doi:10.1016/S0140-6736(13)62630-6

20 Desai S, Rathi N, Kawade A, Venkatramanan P, Kundu R, Lalwani SK, et al. Non-interference of Bovine-Human reassortant pentavalent rotavirus vaccine ROTASIIL ${ }^{\circledR}$ with the immunogenicity of infant vaccines in comparison with a licensed rotavirus vaccine. Vaccine. 2018;36:5519-23. Medline:30104114 doi:10.1016/j.vaccine.2018.07.064

21 Apte A, Roy S, Bavdekar A, Juvekar S, Hirve S. Facilitators and barriers for use of rotavirus vaccine amongst various stakeholders and its implications for Indian context - A systematic review. Hum Vaccin Immunother. 2018;5515:1-8. Medline:29913110 doi:10.1080/21645515.2018.1489190

22 Patil R, Kekan D, Juvekar S. Effect of community level communication on community participation in public health research. IJPHRD. 2017;8:829. doi:10.5958/0976-5506.2017.00437.5

23 Ashraf A, Quaiyum MA, Ng N, Van Minh H, Razzaque A, Masud Ahmed S, et al. Self-reported use of tobacco products in nine rural INDEPTH Health and Demographic Surveillance Systems in Asia. Glob Health Action. 2009;2:1997. Medline:20027256 doi:10.3402/gha.v2i0.1997

24 Van Minh H, Soonthornthada K, Ng N, Juvekar S, Razzaque A, Ashraf A, et al. Blood pressure in adult rural INDEPTH population in Asia. Glob Health Action. 2009;2:2010. Medline:20027254 doi:10.3402/gha.v2i0.2010

$25 \mathrm{Ng}$ N, Hakimi M, Van Minh H, Juvekar S, Razzaque A, Ashraf A, et al. Prevalence of physical inactivity in nine rural INDEPTH Health and Demographic Surveillance Systems in five Asian countries. Glob Health Action. 2009;2:1985. Medline:20027261 doi:10.3402/gha.v2i0.1985 
26 Ingole V, Juvekar S, Muralidharan V, Sambhudas S, Rocklöv J. The short-term association of temperature and rainfall with mortality in Vadu Health and Demographic Surveillance System: a population level time series analysis. Glob Health Action. 2012;5:44. Medline:23195513 doi:10.3402/gha.v5i0.19118

27 Ingole V. Too Hot!: an Epidemiological Investigation of Weather-Related Mortality in Rural India Too Hot! An Epidemiological Investigation of Weather-Related Mortality in Rural India. The Umea University Sweden; 2016.

28 Chadha MS, Hirve S, Dawood FS, Lele P, Deoshatwar A, Sambhudas S, et al. Burden of seasonal and pandemic influenza-associated hospitalization during and after 2009 A(H1N1)pdm09 pandemic in a rural community in India. PLoS One. 2013;8:e55918. Medline:23690913 doi:10.1371/journal.pone.0055918

29 Hirve S, Krishnan A, Dawood FS, Lele P, Saha S, Rai S, et al. Incidence of influenza-associated hospitalization in rural communities in western and northern India, 2010-2012: A multi-site population-based study. J Infect. 2015;70:16070. Medline:25218056 doi:10.1016/j.jinf.2014.08.015

30 Martellet L, Sow SO, Diallo A, Hodgson A, Kampmann B, Hirve S, et al. Ethical challenges and lessons learned during the clinical development of a Group A Meningococcal conjugate vaccine. Clin Infect Dis. 2015;61 suppl 5:S422-7. Medline:26553670 doi:10.1093/cid/civ598

31 Agrawal A, Bhattacharya J, Baranwal N, Bhatla S, Dube S, Sardana V, et al. Integrating health care delivery and data collection in rural India using a rapidly deployable ehealth center. PLoS Med. 2013;10: e1001468. Medline:23825182 doi:10.1371/journal.pmed.1001468

32 Sheikh A, Campbell H, Balharry D, Baqui AH, Bogaert D, Cresswell K, et al. RESPIRE: The National Institute for Health Research's (NIHR) Global Respiratory Health Unit. J Glob Health. 2018;8:020101. Medline:30603074 doi:10.7189/ jogh.08.020101

33 Rudan I, Agrawal D, Hussein N, Cheong AT, Cunningham S, Dockerell D, et al. Setting research priorities for global respiratory medicine within the National Institute for Health Research (NIHR) Global Health Research Unit in Respiratory Health (RESPIRE). J Glob Health. 2018;8:0201314. Medline:30603076 doi:10.7189/jogh.08.020314

34 Hirve S, Chadha M, Lele P, Lafond KE, Deoshatwar A, Sambhudas S, et al. Performance of case definitions used for influenza surveillance among hospitalized patients in a rural area of India. Bull World Health Organ. 2012;90:804-12. Medline:23226892 doi:10.2471/BLT.12.108837

35 Biran A, Rabie T, Schmidt W, Juvekar S, Hirve S, Curtis V. Comparing the performance of Indicators of Hand Washing Practices in Rural India Households. Trop Med Int Health. 2008;13:278-85. Medline:18304276 doi:10.1111/j.1365-3156.2007.02001.x

36 Coton S, Vollmer WM, Bateman E, Marks GB, Tan W, Mejza F, et al. Severity of airflow obstruction in Chronic Obstructive Pulmonary Disease (COPD): Proposal for a new classification. COPD. 2017;14:469-75. Medline:28799856 doi:10 $.1080 / 15412555.2017 .1339681$

37 Muralidharan V, Sussan T, Limaye S, Koehler K, Williams D, Rule A, et al. Field testing of alternative cookstove performance in a rural setting of western India. Int J Environ Res Public Health. 2015;12:1773-87. Medline:25654775 doi:10.3390/ijerph120201773

38 Sussan TE, Ingole V, Kim J-H, McCormick S, Negherbon J, Fallica J, et al. Source of biomass cooking fuel determines pulmonary response to household air pollution. Am J Respir Cell Mol Biol. 2014;50:538-48. Medline:24102120 doi:10.1165/rcmb.2013-02010C

39 Quansah R, Ochieng CA, Semple S, Juvekar S, Emina J, Armah FA, et al. Effectiveness of interventions to reduce indoor air pollution and/or improve health in homes using solid fuel in lower and middle income countries: protocol for a systematic review. Syst Rev. 2015;4:22. Medline:25875770 doi:10.1186/s13643-015-0012-8

40 Pillarisetti A, Ghorpade M, Madhav S, Dhongade A, Roy S, Balakrishnan K, et al. Promoting LPG usage during pregnancy: A pilot study in rural Maharashtra, India. Environ Int. 2019;127:540-9. Medline:30981912 doi:10.1016/j.envint.2019.04.017

41 Patil R. A joyful homecoming. Lancet Respir Med. 2018;6:904. Medline:30629931 doi:10.1016/S2213-2600(18)30474-0

42 Saha SK, Schrag SJ, El Arifeen S, Mullany LC, Shahidul Islam M, Shang N, et al. Causes and incidence of communityacquired serious infections among young children in south Asia (ANISA): an observational cohort study. Lancet. 2018;392:145-59. Medline:30025808 doi:10.1016/S0140-6736(18)31127-9

43 Sankoh O, Herbst AJ, Juvekar S, Tollman S, Byass P, Tanner M. INDEPTH launches a data repository and INDEPTHStats. Lancet Glob Health. 2013;1:e69. Medline:25104154 doi:10.1016/S2214-109X(13)70034-2

44 Sankoh O, IJsselmuiden C. Sharing research data to improve public health: a perspective from the global south. Lancet. 2011;378:401-2. Medline:21803205 doi:10.1016/S0140-6736(11)61211-7

\section{Correspondence to:}

Dr. Sanjay Juvekar, PhD

Vadu Rural Health Program

(VRHP)

Vadu Bk

Taluka Shirur

Dist. Pune 412216

India

sanjay.juvekar@kemhrcvadu.org 